\title{
Attitudes toward Studying, Academic Procrastination and Multiple Mediation Analysis between Them
}

\author{
Banu Yücel TOY*
}

Received: 22 February 2013

Accepted: 03 April 2014

\begin{abstract}
This study aims to examine vocational high school students' attitudes towards studying (valuing studying, willing to study, studying as a habit), academic procrastination behaviors and causal mediation relationship among them. 278 students from three vocational high schools were participated in the study. Correlational research design was applied. In order to collect data, Aitken Academic Procrastination Inventory and Attitudes toward Studying Scale was used and in order to analyze data, ANOVA and multiple mediation analysis methods were utilized. Results showed that students value studying and willing to study but they do not have a tendency for studying as a habit in the same way. Attitudes of girls were more positive than boys and procrastination among girls were significantly lower than boys. Attitudes of students who prefer studying in the morning and afternoon have more positive attitudes towards studying and students who prefer studying in the evening tend to procrastinate more than the others. According to multiple mediation analysis results, when gender of students was controlled, valuing studying indirectly affects academic procrastination through willingness to study and studying as a habit.
\end{abstract}

Keywords: attitudes towards studying, academic procrastination, mediation analysis

\section{Extended Abstract}

Purpose and Significance: There are a variety of factors affecting students' academic achievement. In a review and meta analysis conducted by Steel (2007), it is indicated that academic procrastination and academic performances of students are negatively correlated. There have been a number of studies examining reasons and effects of academic procrastination. Among these studies, as other effective factors in students' learning and success, students' attitudes towards studying, study habits and study strategies are also considered as reasons for students' procrastination behaviors (Balk1s, Duru, Buluş \& Duru 2006; Chissom \& Iran-Nejad, 1992; Erdamar (Koç), 2010; Howell \& Watson, 2007). In this study, students' valuing studying, willingness to study, studying as a habit and academic procrastination and causal mediation relationship among them were studied. It was hypothesized that students who value studying have tendency to willing to study and studying as a habit, and thus, show low procrastination behaviors. Therefore, mediation of willingness to study and studying as a habit in the effect of valuing studying on academic procrastination was examined.

Methods: This study is a causal correlational research study. 278 students from three vocational high schools (one girls' vocational high school (GVHS), one boys' technical and industrial vocational high school (BTIVHS) and one vocational high school (VHS))

Assist. Prof. Dr., Yildiz Technical University, Istanbul, Turkey, banutoy@ yildiz.edu.tr 
in a city in Marmara region were participated in the study. For collecting data, Aitken Academic Procrastination Scale, Attitudes towards Studying Scale (involving three subscales: valuing studying, willingness to study and studying as a habit) and Personal Information Form were used. In order to analyze data, arithmetic means of total scores of each scale were calculated. In comparing scores according to gender, school type and time preferences for studying, independent sample t-test and ANOVA were used. For multiple mediation analysis, INDIRECT macro developed by Preacher and Hayes (2008) was utilized.

Results: Results showed that students value studying and willing to study but they do not have a tendency for studying as a habit in the same way. Students' procrastination level was at moderate level. Attitudes of girls towards studying were more positive than boys and procrastination among girls were significantly lower than boys. However, girls' attitude for studying as habit was lower than boys although the difference was not significant. Similar to gender differences, comparisons according to school type revealed that students in the BTIVHS value studying and are willing to study less than those in the GVHS. The results also showed that procrastination behavior among students in the BTIVHS was higher than those in the GVHS. Attitudes of students who prefer studying in the morning and afternoon have more positive attitudes towards studying and students who prefer studying in the evening have more tendencies to procrastinate than the others. According to multiple mediation analysis results, when gender of students was controlled, valuing studying indirectly affects academic procrastination tendency through willingness to study and studying as a habit.

Discussion and Conclusions: In this study, students' attitudes toward studying were examined under three constructs: valuing studying, willingness to study and studying as a habit. After ascertaining the academic procrastination level among students, a causal relationship between attitudes towards studying and academic procrastination was examined through multiple mediation analysis. Results showed that students' level for valuing studying and willing to study was at good level and their level for studying as a habit and procrastination was at moderate level.

According to gender and school type differences, the study showed that girls value studying and are willing to study more and have fewer tendencies for procrastinating than boys. Önen (2011) in her study also found that girls have more positive attitudes towards studying than boys. On the other hand, despite being insignificant, girls' level for studying as a habit was lower than boys. This means that girls have a problem in realizing studying even though they give importance to studying. Regarding procrastination, it is more widely seen among boys than girls. Altough the related study results are inconclusive, some were consistent with the current study (Balk1s \& Duru, 2009; Balkıs, 2007; Çetin, 2009).

According to preferences for studying, it was observed that attitudes of students who prefer studying in the morning and afternoon have more positive attitude towards 
studying and have less tendency for procrastinating compared to those preferring studying at the evenings. These results are consistent with the related study results (i.e., Balkıs \& Duru, 2009; Ferrari, Harriot, Evans, Lecik-Michna \& Wenger, 1997; Hess, Sherman \& Goodman, 2000).

Study results regarding mediation analysis showed that when gender was controlled, valuing studying has a negative impact on procrastination directly and also indirectly through affecting willingness to study and studying as a habit which have also significant negative impact on procrastination. In other words, willingness to study and studying as a habit are meaningful mediators in explaining the causal relationship between valuing studying and academic procrastination. Regarding the relation between willingness to study and procrastination, it can be said that willingness is related to motivation and there are studies showing that motivation is a predictor of procrastination (Kağan, 2009; Akbay, 2009; Balkıs, Duru, Buluş \& Duru, 2006). Concerning studying as a habit, Jones, Slate, Bell and Saddler (1991) also found that study habits of high school students and their academic procrastination behavior are negatively correlated. According to Jones et al. (1991), students consider studying as an unpleasant activity that would be result in frustration therefore they postpone tasks to the last minute.

There is no study searching the relation between valuing study and procrastination. For this reason, this study results will shed light on the related future studies in this respect. Especially, since this study was conducted in secondary vocational high schools, taking actions for preventing procrastination in earlier times gain more importance. There might be a number reasons for procrastination but at least teachers in secondary schools might start to take precautions such as teaching study and learning strategies, providing a time table, giving tasks that are meaningful and appropriate for the students' level and raising conscientious about the importance of studying before these students reach higher education. 


\title{
Ders Çalışmaya Yönelik Tutum, Akademik Erteleme ve Aralarındaki Çoklu Aracılık İlişkisi
}

\author{
Banu Yücel TOY*
}

Makale Gönderme Tarihi: 22 Şubat 2013

Makale Kabul Tarihi: 03 Nisan 2014

\begin{abstract}
ÖZET: Bu çalışmanın amacı, meslek lisesi öğrencilerinin ders çalışmaya değer verme, ders çalışmaya istekli olma, ders çalışmayı alışkanlık haline getirme ve akademik erteleme eğilimlerini ve aralarındaki aracılık ilişkisini incelemektir. İlişkisel tarama modeli kullanılmış olup veriler akademik erteleme eğilimi ölçeği ve ders çalışmaya yönelik tutum ölçeği ile toplanmıştır. Verilerin analizinde ANOVA ve çoklu aracılık ilişkisi analizinden yararlanılmıştır. Biri kız meslek lisesi, biri erkek endüstri meslek lisesi, diğeri de karma meslek lisesi olmak üzere üç meslek lisesinden 278 öğrenci araştırmaya katılmıştır. Sonuçlar, öğrencilerin ders çalışmaya değer verdiklerini, istekli oldukları ama aynı düzeyde alışkanlık haline getirme eğiliminde olmadıklarını ve akademik erteleme eğilimlerinin orta düzeyde olduğunu ortaya koymuştur. Kız öğrencilerin tutumları erkeklere göre daha olumlu iken akademik erteleme eğilimi ise anlamlı düzeyde daha azdır. Ayrıca sabah ve öğleden sonra çalışanların ders çalışmaya yönelik tutumları gece çalışanlara göre daha olumlu iken, erteleme eğilimi de gece çalışanlarda daha fazla görülmüştür. Çoklu aracılık ilişkisi analizi sonuçlarına göre, cinsiyet faktörü kontrol edildiğinde, ders çalışmaya değer vermenin, ders çalı̧̧maya istekliliği ve alışkanlık haline getirmeye neden olarak akademik erteleme eğilimini anlamlı şekilde yordadığı görülmüştür.
\end{abstract}

Anahtar sözcükler: ders çalışmaya yönelik tutum, akademik ertelemecilik, aracılık ilişkisi

\section{Giriş}

Öğrencilerin akademik performansı, başarıları, öğrenmeleri ve bu süreci etkileyen nedenler her zaman eğitimcilerin, öğretmenlerin, psikolojik danışmanların ve rehber öğretmenlerin, eğitim programcılarının ve politikacıların üzerinde durduğu önemli konulardan biri olmuştur; olmaya da devam edecektir. Akademik başarı ve performans tek bir değişkenle açıklanamayan pek çok etmenin bir arada etkili olduğu karmaşık bir olgudur ve yorumlayabilmek ve anlayabilmek için farklı yaklaşımların kullanılması gerekir (Shah \& Sharma, 2012). Bu sebeple, ilgili taraflara özellikle öğretmenlere öğrencilerin öğrenme ve başarılarında yol gösterici olabilmeleri açısından bu karmaşık olguyu ve nedenlerini açıklamaya katkı sağlayabilecek çalışmaların gerçekleştirilmesi önemlidir. $\mathrm{Bu}$ çalışmada ise, akademik başarı ve performansı etkiledikleri ön kabulüyle öğrencilerin akademik erteleme eğilimleri, ders çalışmaya yönelik tutumları ve aralarındaki ilişki üzerinde durulmuştur.

Öğretimin hangi kademesinde olursa olsun öğrenciler arasında öğretim ile ilgili kendilerine verilen çalışma, etkinlik, ödev, görev ve sorumlulukları erteleme eğilimi karşılaşılan bir durumdur. Ancak bu durumun sıklıkla yaşanması ve alışkanlığa dönüşmesi öğrencinin akademik hayatını olumsuz yönde etkilenmesine neden olmaktadır. Yaptığı yazın taramasında da Steel (2007) ödev notları, sınav sonuçları, genel not ortalaması gibi akademik performans ile erteleme arasında her zaman negatif bir ilişki bulunduğunu ortaya koymuştur.

Erteleme, mantıklı bir gerekçesi olmadan bireyin bir işi yapmayı veya karar almayı kişisel huzursuzluk hissedene kadar geciktirmeye yönelik davranışsal bir eğilimi

\footnotetext{
* Yrd. Doç. Dr., Yıldız Teknik Üniversitesi, İstanbul, banutoy@ yildiz.edu.tr
} 
veya bir kişilik özelliğidir (Milgram, Tal \& Levison, 1998; Solomon \& Rothblum, 1984). Steel (2007) ise mantıklı bir davranış olmadığı görüşünden hareketle ertelemeyi, daha kötüsüne mal olabileceği bilinse bile istenen işin yapılmasının gönüllü olarak geciktirilmesi olarak tanımlamaktadır. Bir başka tanımda da, erteleme kendisinden beklenen bir işi, yapmayı istese bile, istenen süre içerisinde yapmaya bireyin kendisini motive edememesi ve geç kalma stresi yaşayana kadar işe başlamayı geciktirmesi olarak tanımlanmaktadır (Senécal, Koestner \& Vallerand, 1995). Tek boyutlu veya karmaşık (başarısızlık korkusu, risk alma, işin iticiliği, kontrole karşı isyan, bağımlılık ve karar vermede zorluk gibi öncüller bileşeninden oluşan) yapılı bir kişilik özelliği olduğu belirtilen erteleme davranışı beş farklı şekilde görülmektedir. Bunlar, akademik ertelemecilik, genel veya rutin hayatta ertelemecilik, karar vermede ertelemecilik, nevrotik ertelemecilik ve kontrol edilemeyen ve psikolojik fonksiyon bozukluğu olarak ertelemeciliktir (Milgram ve diğerleri, 1998; Watson, 2001). Bunların arasında akademik erteleme ise öğrencilerin ödevlerini yapma ve sınavlara çalışma gibi akademik çalışmaları son dakikaya bırakmaları şeklinde ele alınabilir.

Çalışmaya yönelik tutum, çalışma alışkanlıkları, öz düzenleme gibi etmenlerin yanı sıra, değerlendirilme kaygısı, karar vermede zorlanma, kontrole karşı isyan, bir amacın olmaması, başarısızlık korkusu, risk alma, tembellik, verilen işin itici algılanması ve yeterlik için fazlasıyla mükemmeliyetçi standartların belirlenmesi gibi durumların akademik erteleme davranışı üzerinde etkisi olduğu belirtilmektedir (Burka \& Yuen, 2008; Solomon \& Rothblum, 1984). Steel (2007) tarafindan erteleme üzerine yapılan araştırmaların meta analitik ve kuramsal taraması üzerine yaptığı çalışmasında, erteleme eğilimi ile güçlü ilişkisi olan dört temel etmen üzerine odaklanmıştır. Bunlar, başarabilme beklentisi, işe verilen değer, geciktirmeye yatkınlık ve geciktirmenin kendisidir. Açıklamak gerekirse, başarabilme beklentisi, bireyin işi başarabileceğine dair özgüven eksikliği gibi nedenlerle başarabilme beklentisinin düşük olmasıdır. Işse verilen değer, işin sıkıcı olacağı düşüncesi, çabuk sıkılmaya yatkınlık ve başarma ihtiyacı hissedilmemesi gibi nedenlerle işe değer verilmemesidir. Geciktirmeye yatkınlık ise düşüncesizlik, dikkatini verememe ve oto kontrol yetersizliği gibi öz düzenlemede yaşanan sıkıntılardan kaynaklanmaktadır. Son olarak, geciktirmenin kendisi aslında tanım olarak erteleme ile doğrudan ilgilidir; ancak burada daha çok ödülün veya amacın anlamlı olmaması veya gerçek olamayacak kadar uzak olması gibi nedenlerle işin geciktirilmesi üzerinde durulmaktadır (Burka \& Yuen, 2008; Steel, 2007).

Akademik erteleme, nedenleri ve sonuçları üzerine 1980'li yıllardan beri çok sayıda çalışmalar yapılmıştır (örn., Ferrari \& Tice, 2000; Jones, Slate, Bell \& Saddler, 1991; Onwuegbuzi 2004; Rothblum, Solomon \& Murakami, 1986; Senécal ve diğerleri, 1995; Solomon \& Rothblum, 1984; Watson, 2001). Yapılan çalışmalar, ertelemenin yukarıda belirtildiği gibi pek çok faktörün etkileşimi sonucu ortaya çıkan karmaşık bir davranış olduğunu gösterse de bu etmenler arasında başarısızlık korkusu, işin sıkıcılığı ve motivasyonun öne çıktığını ve düşük not, dersi bırakma gibi akademik açıdan olumsuz sonuçlara neden olduğunu ortaya koymuştur. Ülkemizde de akademik erteleme çalışılan konulardan biridir (Örn., Akbay, 2009; Akça, 2012; Akkaya, 2007; Balkıs, 
2006; 2007; Balkıs \& Duru, 2009; 2010; 2012; Balkıs, Duru, Buluş \& Duru, 2006; Çakıcı, 2003, Çetin, 2009; Ekşi \& Dilmaç, 2010; Gülebağlan, 2003; Kağan, 2009; Özer, 2012; Özer \& Altun, 2011; Uzun Özer, 2005; 2009; 2010). Bu çalışmalarda, akademik ertelemeciliğin nedenleri, cinsiyet, sınıf, bölüm, akademik başarı, çalışma ve öğrenmeye yönelik tutum, motivasyon, başarısızlık korkusu, sınav ve ders çalışmayı tercih ettikleri zaman dilimi, kaygı, konsantrasyon, zaman yönetimi, akademik öz yeterlikler gibi akademik değişkenler ile ve değer, mükemmeliyetçilik, sorumluluk, nevrotizm, düşünme ve karar verme stilleri, özsaygı ve benlik algısı gibi psikolojik-kişilik değişkenleri ile ilişkilere bakılmıştır. Ancak gerek yurtiçinde gerek yurtdışında olsun yapılan çalışmaların üniversite öğrencileri üzerine yoğunlaştığı görülmektedir. Bunun sebebi ise üniversite öğrencileri arasında erteleme eğiliminin daha yaygın olduğu sonucuna varan çalışmalara dayandırılmaktadır. Ortaöğretim öğrencileri üzerine yapılan çalışmalar ise sınırlıdır (Aydoğan, 2008; Çakıcı, 2003; Klassen \& Kuzucu, 2009; Uzun Özer, 2009; Yiğit \& Dilmaç, 2011). Öte yandan bu dönemde öğrenciler arasında görülen erteleme eğiliminin sonraki yıllarda üstesinden gelinmesi zor bir alışkanlığa dönebileceği belirtilmektedir (Owens \& Newbegin, 1997, Aktaran Uzun Özer, 2009: 13). Bu sebeple, zamanında önlemlerin alınması açısından ortaöğretim grubu üzerinde akademik erteleme eğiliminin çalışılması önem arz etmektedir.

Akademik başarı ve performans üzerinde etkili kabul edilen etmenlerden biri olan öğrencilerin ders çalışmaya yönelik tutumları, aynı zamanda çalışma stratejileri ve alışkanlıkları, öz düzenleme becerisi ve motivasyon gibi erteleme eğiliminin akademik nedenleri arasında öne çıkmaktadır (Balkıs ve diğerleri, 2006; Chissom \& Iran-Nejad, 1992; Howell \& Watson, 2007). Bundan dolayı öğrencilerin ders çalışmaya yönelik tutumlarının erteleme eğilimi üzerindeki etkisi de bu çalışma kapsamında ele alınmıştır. Öğrencilerin ders çalışmaya ve öğrenmeye yönelik tutumları, erteleme eğilimi ile negatif yönlü ilişkisi olan ders çalışma stratejileri, ders çalışma alışkanlıkları ve öz düzenleme davranışlarının ortaya çıkmasında etkili kabul edilen faktörlerden birisidir (Erdamar (Koç) 2010; Pintrich \& De Groot 1990). Bu açıdan bakıldığında, ders çalışmaya yönelik tutum ile erteleme eğilimi arasında da negatif yönlü bir ilişkinin olabileceğini beklenebilir. Tutumlar ile davranış arasındaki bu ilişkiyi açıklayan planlanmış davranış teorisine göre, insan davranışlarının ortaya çıkmasını bireyin davranışı yapmaya yönelik niyeti belirlemekte, bireyin davranışa yönelik tutumu ise kişinin davranışa niyetini belirleyen etmenlerden biri olmaktadır (Ajzen, 1991). Akademik başarı ve performans üzerinde etkili olan diğer bir faktörde çalışma sürecidir. Nitekim konuyla ilgili Yeşilyurt (2013) tarafından yapılan bir çalışmanın sonuçları arasında bilişüstü yeti ve başarı odaklı motivasyon birlikte çalışma sürecini anlamlı olarak etkilediği ve açıkladığı ortaya çıkmıştır. Başka bir deyişle, bilişüstü yeti ve başarı odaklı motivasyonun, çalışma sürecinin önemli yordayıcıları olduğu tespit edilmiştir.

$\mathrm{Bu}$ çalışmada tutumun bilişsel, duyuşsal ve davranışsal olmak üzere üç boyutlu olduğu (Chaiken \& Stangor 1987; Tiandis, 1971, Aktaran Tavşanc1l, 2002: 72) görüşünden hareketle öğrencilerin ders çalışmaya yönelik tutumları, ders çalışmaya değer verme, ders çalışmaya istekli olma ve ders çalışmayı alışkanlık haline getirme alt 
boyutlarda incelenmiş ve bu alt boyutların erteleme eğilimi üzerindeki etkisi araştırılmıştır. Ders çalışmaya isteklilik boyutu ile ilgili olarak, bir öğrencinin ders çalışmaya istekli olması onun motivasyon düzeyi ile ilişkilidir ve öz düzenleme kuramına göre kişinin motivasyonu bilişsel süreçlerin kullanımında ve akademik performansında etkili ve önemli bir faktördür (Pintrich \& De Groot, 1990). Bu sebeple, ders çalışmaya istekli olmayan motivasyon düzeyi düşük bir öğrencinin ders çalışmayı, ödev ve etkinlikleri yapmayı ertelemesi muhtemeldir. Ders çalışmayı alışkanlık haline getirme boyutuna ilişkin olarak, ders çalışma alışkanlıklarının tek başına açıklayamasa da erteleme eğilimini etkilediği kabul edilmektedir (Beswick, Rothblum \& Mann, 1988; Solomon \& Rothblum, 1984). Bu sebeple, ders çalışmayı alışkanlık haline getirme boyutuna ilişkin olarak bu davranışa sahip bir öğrencinin erteleme davranışını göstermeyeceği düşünülebilir. Ders çalışmaya değer verme ile erteleme eğilimi arasındaki ilişki açısından ise, Dietz, Hofer ve Fries (2007) bireyin sahip olduğu değerlerin öğrenme etkinliklerini tercihlerinde ve etkinlikleri yapmaya yönelik motivasyonlarında etkili olduğunu ve dolayısıyla erteleme eğiliminde de etkili olacağını ileri sürmektedir. Bu durum değer vermenin ertelemeyi dolaylı olarak etkilediğini göstermektedir. Motivasyonu açıklayan beklenti-değer modeline göre ise bir çalışmanın önemli bulunması ve değer verilmesi motivasyonu belirleyici etmenlerden biridir (Wigfield \& Eccles, 2000). Ulusoy (2004) da öğrencinin sahip olduğu değerleri, motivasyonu etkileyen öğrenciden kaynaklı nedenler arasında göstermektedir. Aynı zamanda değerlerin bireyin davranışları ve alışkanlıkları ile de ilişkili olduğu görüşü kabul edilmektedir (Bardi \& Schwartz, 2003). Bütün bu görüşlerden hareketle, ders çalışmaya istekli olma ve ders çalışmayı alışkanlık haline getirmenin erteleme eğilimini doğrudan etkilediği ancak ders çalışmaya verilen değerin ders çalışmaya istekli olma ve ders çalışmayı alışkanlık haline getirmeyi aracılığıyla erteleme eğilimini dolaylı olarak etkilediği söylenebilir. Bir başka ifade ile, ders çalışmaya önem ve değer veren bir öğrencinin ders çalışmaya istekli olacağı ve ders çalışmayı alışkanlık haline getirebileceği, ders çalışmaya istekli olan ve çalışmayı alışkanlık haline getirmiş bir öğrencinin verilen ödev, proje gibi sorumlulukları erteleme davranışını gösterme eğiliminin düşük olacağı düşünülebilir. Ayrıca farklı sonuçlar elde edilse de cinsiyet hem akademik erteleme hem de ders çalışma alışkanlıkları ve tutumları ve öz düzenleme çalışmalarında genelde farklılık yaratan bir faktör olarak karşımıza çıkmaktadır (Balkıs, 2007; Balkıs \& Duru, 2009; Çetin, 2009; Doyle \& Paludi, 1998; Klassen \& Kuzucu, 2009; Prohaska, Morrill, Atiles \& Perez, 2000; Rothblum ve diğerleri, 1986; Senécal ve diğerleri, 1995; Uzun Özer, Demir \& Ferrari, 2009; Washington, 2004). Bu sebeple, bu çalışmada aracılık ilişkisi bakılırken cinsiyet kontrol değişkeni olarak dahil edilmiştir.

\section{Amaç}

Çalışmanın amacı, meslek lisesi öğrencilerinin akademik başarı ve performanslarında etkili olduğu düşünülen ders çalışmaya değer verme, ders çalışmaya istekli olma, ders çalışmayı alışkanlık haline getirme ve akademik ertelemecilik 
düzeylerini ve aralarındaki aracılık ilişskini incelemektir. Araştırmaya yön veren araştırma soruları ise;

1. Meslek lisesi öğrencilerinin ders çalışmaya yönelik tutumlarını belirleyen ders çalışmaya değer verme, ders çalışmaya istekli olma ve ders çalışmayı alışkanlık haline getirme durumları ile akademik erteleme düzeyleri nedir?

2. Meslek lisesi öğrencilerinin ders çalışmaya değer verme, ders çalışmaya istekli olma ve ders çalışmayı alışkanlık haline getirme durumları ile erteleme eğilim düzeyleri cinsiyete, okul türüne, ders çalışmak için tercih edilen zaman dilimine göre değişmekte midir?

3. Cinsiyet kontrol edildiğinde, ders çalışmaya değer verme; ders çalışmaya istekli olma ve ders çalışmayı alışkanlık haline getirme aracılılığıyla akademik erteleme eğilimini anlamlı düzeyde yordamakta mıdır?

\section{Yöntem}

\section{Araştırmanın Modeli}

$\mathrm{Bu}$ araştırmanın modeli; öğrencilerin akademik erteleme eğilimi ile ders çalışmaya yönelik tutumları arasındaki ilişkiyi ele aldığından dolayı tarama modeli türlerinden ilişkisel tarama modelidir. Tarama modeli, araştırmaya konu olan geçmişte ya da halen var olan bir durumu, olayı, birey ya da nesneyi olduğu haliyle herhangi bir etkileme söz konusu olmadan tanıtmayı amaçlayan araştırma yaklaşımıdır. İlişkisel tarama modeli ise, iki ve daha fazla sayıdaki değişken arasındaki ilişkinin varlığını ve derecesini belirlemek amaciyla gerçekleştirilen araştırma modelleridir (Karasar, 2005). $\mathrm{Bu}$ araştırmada ilişkisel tarama modeli ile öğrencilerin ders çalışmaya yönelik tutumlarının akademik erteleme eğilimini etkilemedeki aracılık ilişkisine bakılmıştır.

\section{Çalışma Grubu}

$\mathrm{Bu}$ çalışma, Marmara bölgesindeki bir ilimizin merkez ilçesinde bulunan üç meslek lisesinde öğrenim gören öğrencileri içermektedir. Bu meslek liselerinden biri kız meslek lisesi, bir diğeri erkek teknik ve endüstri meslek lisesi ve diğeri de karma öğrencilerin okuduğu normal meslek lisesidir. Araştırmaya, 127 kız 151 erkek olmak üzere toplam 278 öğrenci katılmıştır. Bu öğrencilerden, 93'ü kız meslek lisesinden, 98'i karma ticaret ve meslek lisesinden ve 87 'si erkek endüstri meslek lisesindendir.

\section{Veri Toplama Teknikleri}

Bu çalışmada veri toplama aracı olarak Aitken Akademik Erteleme Ölçeği, Ders Çalışmaya Yönelik Tutum Ölçeği ve Kişisel Bilgi Formu kullanılmıştır.

\section{Aitken erteleme eğilimi ölçeği.}

Aitken (1982) tarafından, öğrencilerin akademik görevleri erteleme eğilimlerini ölçmek amacıyla geliştirilen ölçek tek boyutlu toplam 19 maddeden oluşan bir ölçektir. Balkıs (2006) tarafından Türkçeye uyarlaması yapılan ölçek İngilizce çeviri 
işlemlerinden sonra 293 öğrenci üzerinde uygulanmış, elde edilen verilerin madde ve test analizleri ve geçerlik ve güvenirlik çalışmalarından sonra tek boyutlu 16 maddeye indirgenmiştir. 5'li Likert tipinde derecelendirilen ölçekte, öğrencilerin verilen ifadelerin kendilerine ne ölçüde uygun olduğuna dair görüş bildirmeleri istenmiştir (1=Yanlış, 2=Çoğunlukla Yanlış, 3= Bazen Doğru/Bazen Yanlış, 4 = Çoğunlukla Doğru, 4=Doğru). Ölçekten elde edilen puanın yüksekliği o öğrencinin akademik erteleme eğiminin o derecede yüksek olduğuna işaret etmektedir. Ölçeğin iç tutarlık güvenirliği Cronbach $\alpha=.89$, test- tekrar test güvenirliği için yapılan analizlerde Pearson korelasyon katsayısı ise $r=.87$ bulunmuştur. Bu çalışmada yapılan faktör analizi sonucunda ölçeğin tek boyutlu olduğu desteklenmiştir. Açılanan toplam varyans \% 34 , Cronbach $\alpha$ güvenirliği ise .85 'dir.

\section{Ders çalışmaya yönelik tutum ölçeği.}

Ölçek Öztürk, Koç ve Çetin (2004) tarafından öğrencilerin öğrenme ve ders çalışmaya yönelik tutumlarını belirlemek için 5'li Likert tipi ölçek olarak geliştirilmiştir. Öğrencilerin her bir davranışlarına yönelik tutumların düzeyini gösteren seçenekler hiç katılmıyorum (1), çok az katılıyorum(2), orta derecede katıliyorum(3), oldukça katılıyorum(4), ve tamamen katılıyorum şeklinde 5'li likert olarak derecelendirilmiştir. 40 madde olarak başlangıçta geliştirilen ölçek 812 kişi üzerinde uygulanmış ve yapılan analizler sonucunda üç boyuttan oluşan 27 maddeye indirgenmiştir. Bu alt boyutlar, çalışmaya istekli olma (12 madde), çalışmaya değer verme ( 8 madde) ve çalışmayı alışkanlık haline getirme ( 7 madde) olarak isimlendirilmiştir. Her bir alt boyutun Cronbach $\alpha$ güvenirliği sırasıyla, $.87, .85$ ve .82 'dir. Bu çalışmada da yapılan faktör analizi sonucunda, ölçeğin üç boyutlu olduğu ve toplam varyansın \% 58'ini açıkladığ görülmüştür. Bu üç boyutun Cronbach- $\alpha$ güvenirliği ise sırasıyla $.91, .91$ ve .86 'dır.

\section{Kişisel bilgi formu.}

Katılımcıların demografik özelliklerine ilişkin bilgiler "Bilgi Formu" ile toplanmıştır. Bu bilgi formunda, öğrencilerin cinsiyetini, öğrenim gördükleri okul, sınıf ve ders çalışmak için tercih ettikleri zaman dilimini belirlemeye ilişkin sorular bulunmaktadır.

\section{Verilerin Analizi}

Araştırmada elde edilen verilerin her bir ölçek ve alt ölçeklerine verdikleri yanıtlar toplanmış ve istatistiksel analize tabi tutulmuştur. Bu analizler için SPSS 15.0 veri analiz programı kullanılmıştır. Öğrencilerin ölçeklerden aldıkları puanların cinsiyete göre karşılaştırılmasında bağımsız örneklem t-testinden, okul türüne ve çalışmayı tercih ettikleri zaman dilimine göre karşılaştırmalarda ise ANOVA'dan yararlanılmıştır.

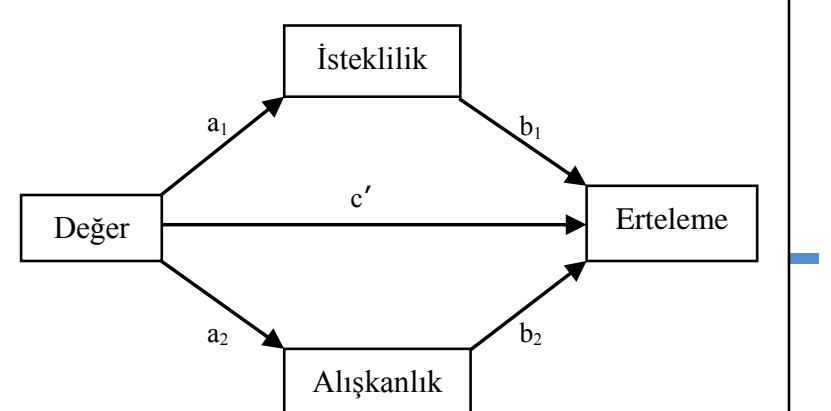


Şekil 1. (A) Ders Çalışmaya Değer Vermenin Akademik Erteleme Üzerine Doğrudan Etkisi; (B) Ders Çalışmaya Değer Vermenin Çalışmaya İstekli Olmayı ve Alışkanlık Haline Getirmeyi Sağlayarak Akademik Erteleme Üzerine Dolaylı Etkisi (Çoklu Aracılık İlişkisi, $\mathrm{M}_{\mathrm{i}}$ : aracı değişkenler)

Öğrencilerin ders çalışmaya verdikleri değerin (Değer) çalışmaya istekli olma (İsteklilik) ve çalışmayı alışkanlık haline getirme (Alışkanlık) aracılığıyla akademik ertelemeyi (Erteleme) etkileme düzeyini incelemek amacıyla yapılan çoklu aracılık (multiple mediation) ilişkisi, Preacher ve Hayes (2008) tarafından geliştirilen SPSS ile kullanılabilen INDIRECT makrosu aracılığıyla incelenmiştir. Aracılık ilişkisi bir bağımsız değişkenin en az bir aracı değişken aracılığıyla bağımlı değişkeni dolaylı olarak yordamasıdır (Preacher \& Hayes, 2008). Çoklu aracılık ilişkisi ise birden fazla aracı değişkenin olması durumunda geçerlidir. Bu çalışmada da, Şekil 1 A'da görülen çalışmaya değer vermesi ile öğrencinin akademik erteleme eğilimi arasındaki doğrudan ilişki yerine, Şekil 1 B'de görülen çoklu aracılık ilişkisine bakılmıştır. Bu aracılık ilişkisinde cinsiyet kontrol değişkeni olarak dahil edilmiştir.

\section{Bulgular}

Ölçeklerden elde edilen puanlar her bir öğrenci için toplanmış ve toplam puanların ortalaması alınmıştır. Ders çalışmaya değer verme alt ölçeğinden elde edilebilecek toplam puan en düşük 8 en yüksek ise 40 'dır. İstekli olma alt ölçeğinin puan aralığı ise 12 ile 60 , alışkanlık haline getirme alt ölçeğinin toplam puan aralı̆̆ 7 ile 35 ve akademik erteleme ölçeğinden elde edilebilecek toplam puan aralığı 16 ile 80 arasında olabilir. Bu çalışmada ise, öğrencilerin değer verme $(\bar{X}=31.29$, ss $=7.64)$ ve istekli olma ( $\bar{X}=44.15$, ss=11.45) puan ortalamaları, öğrencilerin ders çalışmaya oldukça değer verdiklerini ve oldukça istekli olduklarını göstermektedir. Ders çalışmayı alışkanlık haline getirme boyutunda elde edilen puan ortalaması ( $\bar{X}=21.56$, ss $=6.54$ ) ile erteleme puan ortalaması ( $\bar{X}=38.54, \quad \mathrm{ss}=11.82)$ öğrencilerin orta düzeyde ders çalışmayı alışkanlık haline getirme ve erteleme davranışı gösterme eğiliminde olduklarına işaret etmektedir. 
Öğrencilerin ders çalışmaya dair tutumları ile akademik erteleme eğilimlerinin cinsiyete göre farklılaşıp farklılaşmadığına ilişkin yapılan bağımsız örneklem t-testi sonuçları Tablo 1'de verilmiştir. Ders çalışmaya değer verme, ders çalışmaya istekli olma konusunda kız öğrenciler erkek öğrencilerden daha olumlu bir tutum içersindedir. $\mathrm{Bu}$ bulgu ile doğru orantılı olarak kızlar erkeklerden anlamlı düzeyde daha az erteleme eğilimi göstermektedir. Bu test sonuçlarının etki büyüklüğü ise, değer ve isteklilik için orta, erteleme eğilimi için ise büyüktür. Çünkü, Cohen (1992) kriterine göre etki büyüklüğü $\left(\eta^{2}\right), 0.20$ ise küçük, 0.50 ise orta, 0.80 ise büyüktür. Diğer taraftan ders çalışmayı alışkanlık haline getirmeye yönelik tutum anlamlı olmamakla birlikte kızlarda daha düşük çıkması dikkate değer bir bulgudur.

Tablo 1

Cinsiyet Farklılı̆̆ına İlişkin Bă̆ımsız Örneklem t-Testi Sonuçları

\begin{tabular}{lllllllll}
\hline & Cinsiyet & $\boldsymbol{n}$ & $\bar{X}$ & $\boldsymbol{s s}$ & $\boldsymbol{t}$ & $\boldsymbol{p}$ & $\boldsymbol{\eta}^{2}$ \\
\hline Değer & Kiz & 127 & 33.22 & 5.99 & 4.09 & $0.00^{*}$ & 0.48 \\
& Erkek & 151 & 29.66 & 8.47 & & & \\
\hline İsteklilik & Kiz & 127 & 46.86 & 10.62 & 3.71 & $0.00^{*}$ & 0.45 \\
& Erkek & 151 & 41.86 & 11.65 & & & \\
\hline Alışkanlık & Kiz & 127 & 20.89 & 5.51 & -1.61 & 0.11 & \\
& Erkek & 151 & 22.12 & 7.27 & & & \\
\hline Erteleme & Kuz & 127 & 34.24 & 10.36 & -5.88 & $0.00^{*}$ & 0.71 \\
& Erkek & 151 & 42.15 & 11.80 & & & \\
\hline
\end{tabular}

*0.05 düzeyinde anlamlıdır.

Öğrencilerin okudukları okul türüne göre farklılığın olup olmadığına ilişkin yapılan analizlerin sonuçları Tablo 2'de verilmiştir. Bu sonuçlara göre, ders çalışmayı alışkanlık haline getirme davranışının bütün liselerde benzer yapıda olduğu görülmüştür. Ancak çalışmaya değer verme, çalışmaya istekli olma ve erteleme eğilimlerinin okullara göre farklılaştığı bulgusu elde edilmiştir. Fakat bu farklılıkların etki büyüklükleri küçüktür. Hangi okul türünün farklılık gösterdiğini tespit etmek amacıyla çoklu karşılaştırma (post hoc) testleri kullanılmıştır. Çalışmaya değer verme boyutunda grupları karşılaştırmak için varyansların ve grupların eşit olmadı̆̆ durumlarda güçlü bir istatistik olarak kabul edilen Games-Howel testi, diğer değişkenlerde ise varyansların eşitliği koşulu sağlandığından ve grup büyüklükleri arasında da çok fark olmadığından bu durumlarda kullanılması önerilen Gabriel testi (Field, 2009) kullanılmıştır. Yapılan testler sonucunda, erkek teknik ve endüstri meslek lisesi öğrencilerinin ders çalışmaya değer verme ve ders çalışmaya istekli olma durumunun karma ve kız meslek liselerinden anlamlı boyutta daha düşük olduğu, karma ve kız meslek lisesi öğrencileri arasında ise fark olmadığı görülmüştür. Akademik erteleme eğilimi açısından ise, bütün grupların birbirinden anlamlı düzeyde farklı olduğu erkek teknik ve endüstri meslek lisesi öğrencileri arasında erteleme eğiliminin 
diğer okullara göre fazla olduğu kız meslek lisesi öğrencilerinin ise en az erteleme eğilimi gösteren grup olduğu görülmüştür.

Tablo 2

Okul Türüne Farklılı̆̆ına İlişkin ANOVA Sonuçları

\begin{tabular}{|c|c|c|c|c|c|c|c|}
\hline & Meslek Lisesi Türü & $\mathbf{n}$ & $\bar{X}$ & ss & $F$ & $p$ & $\eta^{2}$ \\
\hline \multirow{3}{*}{ Değer } & $\mathrm{K}_{1 \mathrm{z}}$ & 93 & 33.03 & 5.81 & $14.09^{\mathrm{a}}$ & $0.00^{*}$ & 0.12 \\
\hline & Karma & 98 & 33.08 & 6.57 & & & \\
\hline & Erkek & 87 & 27.40 & 8.99 & & & \\
\hline \multirow{3}{*}{ İsteklilik } & $\mathrm{K}_{1 \mathrm{z}}$ & 93 & 46.03 & 10.32 & 14.59 & $0.00^{*}$ & 0.09 \\
\hline & Karma & 98 & 46.98 & 10.72 & & & \\
\hline & Erkek & 87 & 38.94 & 11.74 & & & \\
\hline \multirow{3}{*}{ Alışkanlık } & $\mathrm{K}_{1 \mathrm{z}}$ & 93 & 20.46 & 5.28 & $2.74^{\mathrm{a}}$ & 0.07 & \\
\hline & Karma & 98 & 22.52 & 7.00 & & & \\
\hline & Erkek & 87 & 21.66 & 7.11 & & & \\
\hline \multirow{3}{*}{ Erteleme } & $\mathrm{K}_{1 \mathrm{z}}$ & 93 & 33.74 & 9.70 & 17.05 & $0.00^{*}$ & 0.11 \\
\hline & Karma & 98 & 38.69 & 11.88 & & & \\
\hline & Erkek & 87 & 43.48 & 11.86 & & & \\
\hline
\end{tabular}

*0.05 düzeyinde anlamlıdır.

${ }^{a}$ Levene testi anlamlı çıktığı için varyansların homojenliği varsayımı reddedilmiştir. Bu sebeple bu durumlarda kullanılan Welch $\mathrm{F}$ istatistiği sonucu verilmiştir.

Öğrencilerin ders çalışmayı tercih ettikleri zaman dilimine göre ders çalışmaya yönelik tutumlarında ve erteleme eğilimlerinde farklılığın olup olmadığına ilişkin yapılan ANOVA sonuçları Tablo 3'de verilmiştir. Elde edilen sonuçlar, ders çalışmaya yönelik tutumun bütün alt boyutlarında ve erteleme eğilimlerinde anlamlı farklılığın olduğunu ancak farklılığın etki büyüklüğünün küçük olduğunu göstermiştir. Farklılığın hangi zaman dilimlerinden kaynaklandığını tespit etmek amacıyla yapılan çoklu karşılaştırmalarda, çalışmaya değer verme, çalışmaya istekli olma ve akademik erteleme için Games-Howel, ders çalışmayı alışkanlık haline getirme için ise varyansların eşit olduğu ancak grup büyüklüklerinin birbirinden oldukça farklı olduğu durumlarda kullanılan Hochberg's GT2 (Field, 2009) kullanılmıştır. Test sonuçları, ders çalışmaya değer verme, ders çalışmaya istekli olma ve ders çalışmayı alışkanlık haline getirme davranışlarının sabah erken saatlerde çalışanlarda, öğlen saatleri ve gece geç saatlerde çalışanlara göre anlamlı düzeyde daha yüksek olduğu görülmüştür. Akademik erteleme eğiliminin ise gece geç saatlerde ders çalışanlarda, sabah erken saatlerde çalışanlara göre anlamlı düzeyde yüksek olduğu, diğer zaman dilimlerinde çalışanlarda ise farklılığın olmadığı ortaya çıkarılmıştır.

Tablo 3

Ders Çalışmayı Tercih Ettikleri Zaman Dilimleri Farklılığına İlişkin ANOVA Sonuçları 


\begin{tabular}{|c|c|c|c|c|c|c|c|}
\hline & Zaman Dilimleri & $n$ & $\bar{X}$ & $s \boldsymbol{s}$ & $\boldsymbol{F}$ & $p$ & $\eta^{2}$ \\
\hline \multirow{4}{*}{ Değer } & Sabah Erken Saatler & 76 & 33.72 & 7.01 & $4.63^{\mathrm{a}}$ & $0.00^{*}$ & 0.05 \\
\hline & Öğlen Saatleri & 48 & 29.35 & 7.57 & & & \\
\hline & Okul Çıkışı (Akşam) & 102 & 31.19 & 7.25 & & & \\
\hline & Gece Geç Saatlerde & 52 & 29.69 & 8.53 & & & \\
\hline \multirow{4}{*}{ İsteklilik } & Sabah Erken Saatler & 76 & 48.78 & 9.47 & $7.43^{\mathrm{a}}$ & $0.00^{*}$ & 0.07 \\
\hline & Öğlen Saatleri & 48 & 42.06 & 11.24 & & & \\
\hline & Okul Çıkışı (Akşam) & 102 & 41.86 & 12.37 & & & \\
\hline & Gece Geç Saatlerde & 52 & 43.80 & 10.65 & & & \\
\hline \multirow{4}{*}{ Alışkanlık } & Sabah Erken Saatler & 76 & 23.66 & 6.69 & 6.24 & $0.00^{*}$ & 0.06 \\
\hline & Öğlen Saatleri & 48 & 19.02 & 5.83 & & & \\
\hline & Okul Çıkışı (Akşam) & 102 & 21.91 & 6.60 & & & \\
\hline & Gece Geç Saatlerde & 52 & 20.15 & 5.87 & & & \\
\hline \multirow{4}{*}{ Erteleme } & Sabah Erken Saatler & 76 & 34.76 & 13.03 & $3.40^{\mathrm{a}}$ & $0.02^{*}$ & 0.04 \\
\hline & Öğlen Saatleri & 48 & 40.42 & 12.97 & & & \\
\hline & Okul Çıkışı (Akşam Üzeri) & 102 & 39.18 & 10.01 & & & \\
\hline & Gece Geç Saatlerde & 52 & 41.05 & 11.16 & & & \\
\hline
\end{tabular}

* 0.05 düzeyinde anlamlıdır.

${ }^{a}$ Levene testi anlamlı çıktığı için varyansların homojenliği varsayımı reddedilmiştir. Bu sebeple bu durumlarda kullanılan Welch F istatistiği sonucu verilmiştir.

Ders çalışmaya değer vermenin, ders çalışmaya istekli olma ve alışkanlık haline getirme aracılı̆̆ıla erteleme eğilimi üzerine dolaylı etkisinin cinsiyet kontrol edildiğinde (Şekil 1-B) incelenmesinde çoklu aracılık analizi gerçekleştirilmiştir. Bu analizler öncesinde değişkenler arasındaki korelasyona bakılmıştır. Bütün değişkenler arasındaki Pearson korelasyon katsayıları .01 düzeyinde anlamlı çıkmıştır (Tablo 4). Ders çalışmaya değer vermenin diğer değişkenlerle arasındaki ilişkinin yüksek olduğu görülmüştür. Bütün bağımsız değişkenlerin Erteleme ile arasında ise anlamlı ve negatif yönlü ilişki olduğu görülmüsstür. Ancak, bütün bağımsız değişkenler arasındaki anlamlı ilişki aynı zamanda çoklu doğrusal bağıntı (multicollinearity) olduğuna da işaret etmektedir. Bu durum, söz konusu değişkenlerin dahil edildiği çoklu regresyon analizi yapmanın uygun olmadığını ve bu sebeple aracılık ilişkisi analizinin daha doğru bir yaklaşım olduğunu göstermektedir. Aracı değişkenler arasındaki ilişkiye bakıldığında ise, Alışkanlık ve İsteklilik arasındaki ilişkinin anlamlı ancak küçük $(<0.30)$ olması aracılık ilişkisi analizi sonuçlarını etkileyecek aracı değişkenler arasında doğrusal bağıntı (collinearity) olmadığına işaret etmiştir. 
Tablo 4

Değişkenler Arasındaki Pearson Korelasyon Katsayıları

\begin{tabular}{lrrrr}
\hline & Değer & \multicolumn{2}{c}{ İsteklilik } & \multicolumn{2}{c}{ Alışkanlık } & \multicolumn{2}{c}{ Erteleme } \\
\hline Değer & 1 & $.62^{* *}$ & $.48^{* *}$ & $-.59^{* *}$ \\
İsteklilik & & 1 & $.27^{* *}$ & $-.59^{* *}$ \\
Alışkanlık & & & 1 & $-.32^{* *}$ \\
\hline Erteleme & & & & 1 \\
\hline${ }^{*} 0.05$ düzeyinde anlamlıdır. & & & &
\end{tabular}

*0.05 düzeyinde anlamlıdır.

Çoklu aracılık ilişkisine ilişkin sonuçlar ise Tablo 5 ve 6'da verilmiştir. Tablo 5'deki sonuçlara göre ders çalışmaya değer verme, çalışmaya isteklilik ve çalışmayı alışkanlık haline getirmeyi anlamlı şekilde yordamaktadır (Şekil 2). Ders çalışmaya değer vermenin erteleme eğilimi üzerindeki etkisi kontrol edildiğinde, çalışmaya istekli olma ve ders çalışmayı alışkanlık haline getirme ertelemeyi negatif yönde anlamlı şekilde yordamaktadır. Aracı değişkenlerin dahil edilmediği bir durumda ders çalışmaya değer verme, akademik erteleme eğilimini anlamlı bir şekilde yordarken $(\beta=-.78$, $\mathrm{t}=$ $11.03, \mathrm{p}<.05)$, aracı değişkenler dahil edildiğinde de hala anlamlı bir şekilde yordadığ ancak katsayının anlamlı bir şekilde düştüğü görülmektedir $(\beta=-.39, \mathrm{t}=-4.24, \mathrm{p}<.05)$. Cinsiyetin $(0=$ erkek, $1=\mathrm{k} 1 \mathrm{z})$ erteleme eğilimi üzerindeki kısmi etkinin ise anlamlı olduğu, negatif çıkması da kız öğrencilerin erkek öğrencilerinden daha az erteleme eğilimi gösterdiğini ifade etmektedir. Bu sonuçlardan, cinsiyet kontrol edildiğinde ders çalışmaya değer vermenin akademik erteleme eğilimi üzerine etkisinde, ders çalışmaya istekli olmanın ve alışkanlık haline getirmenin anlamlı aracı değişkenler olduğu anlaşılmaktadır.

Şekil 2. Çoklu Aracılık İlişkisi Analizi Sonuçlarına Göre İlişki Katsayıları
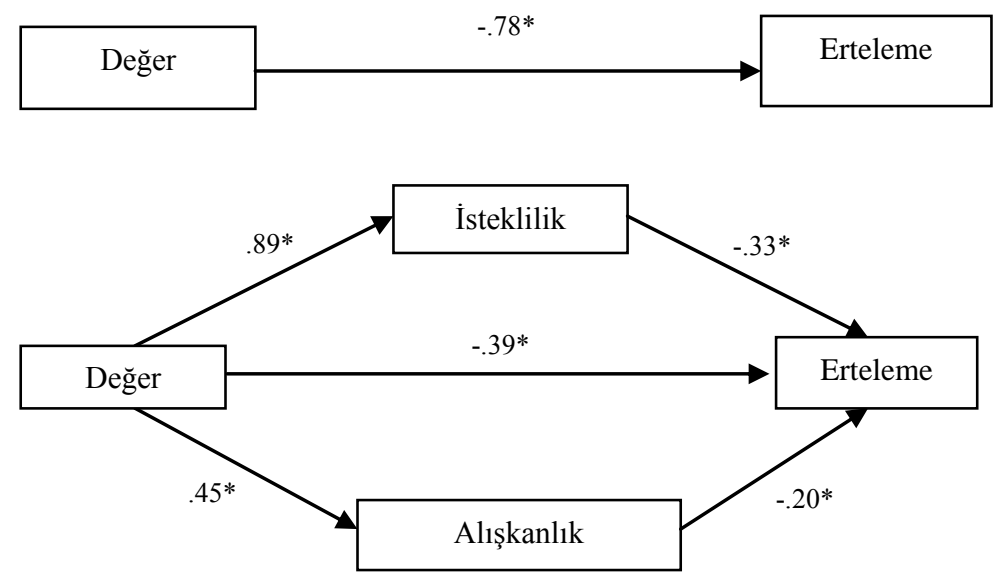
Tablo 5

Değişkenlerinin Doğrudan Etkilerine İlişkin Analiz Sonuçları

\begin{tabular}{|c|c|c|c|c|}
\hline & Katsayı & Standart hata & $t$ & $p$ \\
\hline \multicolumn{5}{|l|}{ Değer’in Aracı Değişkenlere Etkisi (a) } \\
\hline İsteklilik & .89 & .07 & 12.26 & .00 \\
\hline Alışkanlık & .45 & .05 & 10.04 & .00 \\
\hline \multirow{2}{*}{\multicolumn{5}{|c|}{$\begin{array}{l}\text { Değerin Erteleme Üzerine Etkisi Kontrol } \\
\text { Edildiğinde Aracı Değişkenlerin Ertelemeye } \\
\text { Etkisi (b) }\end{array}$}} \\
\hline & & & & \\
\hline İsteklilik & -.33 & .06 & -6.13 & .00 \\
\hline Alışkanlık & -.20 & .09 & -1.32 & .02 \\
\hline \multicolumn{5}{|l|}{ Değerin Ertelemeye Toplam Etkisi (c) } \\
\hline Değer & -.78 & .07 & -11.03 & .00 \\
\hline \multicolumn{5}{|l|}{ Değerin Ertelemeye Doğrudan Etkisi (c') } \\
\hline Değer & -.39 & .09 & -4.24 & .00 \\
\hline \multicolumn{5}{|l|}{ Cinsiyetin Ertelemeye Kısmi Etkisi } \\
\hline Cinsiyet & -4.62 & 1.04 & 4.42 & .00 \\
\hline
\end{tabular}

Diğer taraftan, çoklu aracılık ilişkisinin incelenmesinde, Preacher ve Hayes (2008), doğrudan etki yerine katsayılar çarpımı (Product of coefficients $=a_{i} b_{i}$ ) ve önyükleme (Bootstrapping) yaklaşımları gibi aracı değişkenler dahil edildiği bağımsız değişkenin bağımlı değişkene dolaylı etkisinin incelenmesini önermektedir. Özellikle bu yaklaşımlardan, katsayılar çarpımı yaklaşımının, katsayı çarpımlarının normal dağıldığ varsayımına dayalı olduğunu ancak bu varsayımın test edilememe veya sağlanamama durumlarına karşılık önyükleme sonuçlarını değerlendirmenin diğer yaklaşımlara göre daha uygun olacağı ifade edilmektedir. Bu doğrultuda, Tablo 6'da verilen önyükleme sonuçları dikkate alındığında, cinsiyet faktörü kontrol edildiğinde, ders çalışmaya istekli olma ve ders çalışmayı alışkanlık haline getirme aracılığıyla ders çalışmaya değer vermenin, erteleme eğilimine anlamlı düzeyde etki ettiği görülmüştür. Çünkü önyükleme analizi sonuçlarına göre, ders çalışmaya istekli olma değişkeni için verilen güven aralığı (-.44 ile -.20) ve ders çalışmayı alışkanlık haline getirme için güven aralığında (-.18 ile -.01) sıfirın olmaması, değer vermenin bu aracı değişkenlerin her birinin ayrı ayrı aracılığında erteleme eğilimi üzerinde etkisinin anlamlı olduğuna işaret etmektedir. Her iki değişken birden dahil edildiğinde ise değerin erteleme eğilimi üzerinde toplam dolaylı etkisinin yine sıfır içermeyen bir güven aralığında olması (-.54 ile -.26), her iki değişkenin aynı anda aracı olduğu durumda da bu etkinin anlamlı olduğuna işaret etmektedir. Çoklu aracılık ilişkisi sonuçlarını özetlemek gerekirse, cinsiyet kontrol edildiğinde, ders çalışmaya değer verme, ders çalışmaya istekli olmaya ve ders çalışmayı alışkanlık haline getirme davranışlarını etkileyerek dolaylı olarak erteleme eğilimini etkilemektedir. Bu ilişkide ders çalışmaya istekli olma ve alışkanlık haline getirme anlamlı birer aracı değişkendir. 


\section{Tablo 6}

Değerin Erteleme Üzerine Aracı Değişkenler Aracılı̆̆ılla Dolaylı Etkisine İlişkin Analiz Sonuçları

\begin{tabular}{cccc}
\hline & \multicolumn{3}{c}{ Önyükleme (Bootstrapping) sonuçları } \\
\cline { 3 - 4 } & & \multicolumn{3}{c}{ Yanlılık düzeltilmiş ve hızlandırılmış güven } \\
& Etki & Alt & Üs 1 \\
\cline { 3 - 4 } & -.30 & -.41 & -.20 \\
İsteklilik $\left(\mathrm{a}_{1} \mathrm{~b}_{1}\right)$ & -.09 & -.18 & -.01 \\
Alışkanlık $\left(\mathrm{a}_{2} \mathrm{~b}_{2}\right)$ & -.39 & -.54 & -.26 \\
Toplam $\left(\mathrm{a}_{1} \mathrm{~b}_{1}+\mathrm{a}_{2} \mathrm{~b}_{2}\right)$ & & & \multicolumn{2}{c}{. } \\
\hline
\end{tabular}

\section{Sonuç ve Tartışma}

$\mathrm{Bu}$ çalışmada, meslek lisesi öğrencilerinin ders çalışmaya yönelik tutumları, akademik erteleme eğilimleri ve tutumları ile erteleme eğilimleri arasındaki aracılık ilişkisi incelenmiştir. Çalışma sonuçları ders çalışmaya tutumun alt boyutları olan ders çalışmaya ortalama olarak oldukça değer verdiklerini ve ders çalışmaya oldukça istekli olduklarını ancak ders çalışmayı alışkanlık haline getirme ve erteleme eğilimlerinin orta düzeyde olduğunu göstermiştir. Bu sonuç her ne kadar öğrenciler ders çalışmaya önem verseler dahi bunu eyleme dönüştürme konusunda o derecede başarılı olamadıklarını ve erteleme eğilimi içerisine girdiklerini göstermektedir.

Cinsiyet açısından karşılaştırma yapıldığında çalışma sonuçları kız öğrencilerin ders çalışmaya daha çok değer verdiklerini ve daha istekli olduklarını ortaya koymaktadır. Okul türüne göre karşılaştırma yapıldığında da erkek teknik ve endüstri meslek lisesinde okuyan öğrencilerin diğer gruplardan anlamlı düzeyde daha düşük tutumda olmaları cinsiyet faktörü ile ilişkili olduğunu göstermektedir. Ders çalışmaya yönelik tutumun bütün alt boyutlarının birlikte değerlendirildiği Önen (2011) tarafından yapılan çalışmada da, kız öğrencilerin tutumunun erkeklerden anlamlı düzeyde daha olumlu olduğu görülmüştür. Ancak ders çalışmayı alışkanlık haline getirmede, cinsiyete göre anlamlı bir farklılık bulunmamış olmakla birlikte kız öğrencilerin ders çalışmayı alışkanlık haline getirme eğilimi erkeklerden daha düşüktür. Bu durum okul türüne göre karşılaştırma sonuçlarına da yansımıştır. Kız meslek lisesi öğrencileri ile erkek meslek lisesi arasında fark bulunmamıştır ama ortalamalara bakıldığında kız meslek lisesindeki öğrencilerin alışkanlık haline getirme eğilimi erkek meslek lisesinden daha düşüktür. $\mathrm{Bu}$ durum kız öğrencilerin ders çalışmaya daha çok değer vermelerine ve daha istekli olmalarına rağmen uygulamaya dökmelerinde sorun olduğunu göstermektedir. Erteleme eğilimi ise, kız öğrenciler arasında daha düşüktür. İlgili çalışmalarda elde edilen sonuçlar ise farklılık göstermektedir. Balkıs ve Duru (2009), Balkıs (2007) ve Çetin (2009) üniversite öğrencileri üzerine yaptıkları çalışmada erteleme eğiliminin kızlarda daha düşük olduğu sonucuna ulaşmıştır. Bu bakımdan, bu çalışmadaki öğrencilerin üniversite öğrencileri ile benzer özellikler gösterdikleri söylenebilir. Diğer taraftan ortaöğretim öğrencileri üzerine yaptıkları çalışmalarında, Uzun Özer (2009), Klassen ve 
Kuzucu (2009) ve Yiğit ve Dilmaç (2011) ise cinsiyetler arasında erteleme eğilimi açısından bir fark bulamamıştır. Bu sonuçların tersine, Rothblum ve diğerleri (1986) ise çalışmalarında, yüksek erteleme eğiliminin kız öğrencileri arasında erkeklerden daha fazla görüldüğü sonucuna ulaşmıştır.

Ders çalışmak için tercih edilen zaman dilimine göre öğrenciler arasında sabah erken ve öğle saatlerinde ders çalışanların ders çalışmaya yönelik tutumlarının gece geç saatlerde çalışanlara göre daha olumlu olduğu, erteleme eğiliminin de gece geç saatlerde çalışanlar arasında diğer zaman dilimlerinde çalışanlardan daha fazla olduğu görülmüştür. Bu sonuçlar birbirini destekler niteliktedir. Çünkü ders çalışmaya yönelik daha olumlu tutumu olan öğrencilerin, ders çalışmayı geç saatlere bırakmak yerine erkenden işlerini yapma eğiliminde oldukları için erteleme eğilimlerinin de bu gruplarda daha düşük olacağı söylenebilir. Bu bulgular, erteleme davranışı gösterenlerin işlerini yapmak için hangi zaman dilimlerini tercih ettiklerine yönelik yapılan çalışma sonuçları ile tutarlık göstermektedir (Balkıs \& Duru, 2009; Balkıs, 2007). Benzer şekilde, Ferrari, Harriot, Evans, Lecik-Michna ve Wenger (1997) de yaptıkları çalışmada erteleme davranışı gösteren bireylerin günlük işlerini gündüz ve sabah erken vakitler yerine geç saatlerde yapmayı tercih ettikleri sonucuna ulaşmışlardır. Hess, Sherman ve Goodman (2000) da öğrenciler arasında günlük işlerini akşamları yapmayı tercih edenlerin daha çok erteleme eğilimi gösterdiklerini bulmuşlardır.

$\mathrm{Bu}$ çalışmada, öğrencilerin ders çalışma tutum ve erteleme eğilimlerinde cinsiyet farklılığına dair elde edilen bulgular, aracılık ilişkisinde cinsiyetin kontrol değişkeni olarak analizlere dahil edilmesini desteklemiştir. Bu sebeple, cinsiyet kontrol edilerek yapılan çoklu aracılık ilişkisi analiz sonuçları, ders çalışmaya değer vermenin aracı değişkenlerin varlığında da yokluğunda da anlamlı bir şekilde akademik ertelemeyi yordadığını göstermiştir. Ancak, ders çalışmaya istekli ve ders çalışmayı alışkanlık haline getirmenin aracı değişken olduğu durumda değer vermenin erteleme eğilimini yordama katsayısının düşmesi kısmi aracılık ilişkisinin olduğunu göstermektedir. Diğer yandan, bulgulara göre değer verme, ders çalışmaya istekli olma ve alışkanlık haline getirmeyi anlamlı ve pozitif yönde; bütün değişkenlerin her biri ise erteleme eğilimini anlamlı ve negatif yönde yordamaktadır. Bu durumda, ders çalışmaya değer vermenin istekli olma ve alışkanlık haline getirmeyi etkileyerek erteleme eğilimini dolaylı olarak etkilediği görüşü desteklenmiş bulunmaktadır. Bir başka ifade ile, ders çalışmaya değer veren öğrencilerin, ders çalışmaya daha istekli ve alışkanlık haline getirme eğiliminde olduklarını ve böylelikle daha az erteleme eğilimi göstereceklerini beklemek mümkün olabilir. Motivasyonun akademik ertelemeyi anlamlı yordadığ 1 çeşitli çalışmalarda görülmüştür (Kağan, 2009; Akbay, 2009; Balkıs ve diğerleri, 2006). Bu çalışmada motivasyon çalışılmamış bir değişken olsa da, istekli olmanın motivasyon ile ilişkili olduğu düşünüldüğünde, ders çalışmaya istekli olmanın ertelemeyi neden anlamlı düzeyde etkilediğini anlamak mümkün olabilir. Ders çalışmayı alışkanlık haline getirmenin erteleme üzerine etkisi ile ilgili olarak, Jones ve diğerleri (1991), lise öğrencileri üzerinde yaptıkları çalışmada lise öğrencilerinin çalışma alışkanlıkları ile erteleme eğilimleri arasında anlamlı düzeyde negatif ilişki olduğunu bulmuşlar ve zayıf 
çalışma alışkanlığının erteleme eğilimine neden olabileceği sonucuna varmışlardır. Jones ve diğerlerine (1991) göre, akademik becerileri yetersiz olan öğrenciler ders çalışmayı hüsrana ve başarısızlığa neden olan mutsuzluk verici bir etkinlik olduğunu düşündüklerinden dolayı son dakikaya kadar ders çalışmayı ertelemektedir. Bu konuda Özer ve Altun (2011) öğrencilerin erteleme davranışlarının nedenlerini araştırmışlar ve performanstan kaçınma eğilimde ve sorumluluk duygusu düşük öğrencilerin başarısızlık korkusu ve tembellik nedeniyle akademik çalışmaları erteledikleri sonucuna ulaşmışlardır. Söz konusu bu faktörlerin ister değer verme, ister istekli olma, ister alışkanlık haline getirme olsun ders çalışmaya yönelik tutumları ve dolayısıyla erteleme davranışını etkiledikleri düşünülebilir. $\mathrm{Bu}$ çalışmada kısmi aracılık ilişkisinin bulunması, ders çalışmaya değer vermemenin erteleme eğilimine neden olmasında burada çalışılan değişkenlerin dışında başka değişkenlerin de aracılık ettiğine işaret etmektedir ve tembellik, hedef belirleyebilme, başarısızlık korkusu, işin sıkıcılığı gibi akademik değişkenlerin etkisinin de birlikte incelenmesinin faydalı olabileceği düşünülmektedir.

Akademik becerilerin, tutumların ve güdülenmeyi etkileyecek etmenlerin öncelikle öğretmenler tarafından farkına varılması ve gereken önlemlerin alınması önemlidir. Bu çalışma, ders çalışmaya yönelik tutumların erteleme eğilimi üzerinde etkisini ortaya koymaktadır. Bu sebeple, öğretmenlerin öğrencilerine ders çalışmaktan uzaklaşmak yerine sevdirebilecekleri ve anlam kazandırabilecekleri çalışmalar vermeleri, ders çalışmanın öğrencilerin akademik hayatlarındaki öneminin farkına varılmasının sağlanması açısından önemlidir. Çalışma alışkanlıklarının erteleme eğilimi ile anlamlı bir ilişki göstermesi öğretmenlerin öğrencilerine öğrenme stratejilerini kazandırmasının önemine de işaret etmektedir. Çünkü bu çalışmada öğrencilerin ortalama olarak öğrenmeye değer verdikleri ve istekli oldukları görülürken, alışkanlığa dönüştürme konusunda özellikle kız öğrencilerinin ve kız meslek lisesi öğrencilerinin sıkıntıları oldukları anlaşılmaktadır. Bu öğrencilere uygun öğrenme stratejilerinin kazandırılması ile bu sorunun kolaylıkla aşılacağı düşünülebilir. Bunun yanı sıra öğrenci düzenli ve programlı ders çalışma alışkanlığı kazandıracak etkinlikler yapılması erteleme eğilimini de azaltacaktır. Jones ve diğerleri (1991) bu konuda öğrencinin son dakikaya kadar beklemesini engelleyecek şekilde bir çalışma takviminin belirlenmesinin faydalı olabileceğini belirtmektedir. Ayrıca, öğrencilerin ortaöğretim öğrencileri olduğu düşünüldüğünde, yüksek öğrenime geçmeden öğrencilere ders çalışmanın öneminin aşılanması, onlara yapmaktan keyif duyacakları öğrenme etkinliklerinin ve ortamının hazırlanması, derslerini zamanında yapmalarına yönelik planlı çalışma alışkanlığının kazandırılması onların sadece şimdiki öğrenim hayatlarında başarılarının önündeki engellerden biri olan erteleme eğilimini azaltmakta önemli olmayacak aynı zamanda bir üst öğrenimlerinde de bu sorunun üstesinden gelmede gereken önlemin zamanında alınmasını sağlayacaktır. 


\section{Kaynakça}

Akbay, S. E. (2009). Cinsiyete göre üniversite ögrencilerinde akademik erteleme davranışı: Akademik güdülenme, akademik özyeterlik ve akademik yükleme stillerinin rolü. Yayınlanmamış yüksek lisans tezi, Mersin Üniversitesi, Mersin.

Akça, F. (2012). An Investigation into the self-handicapping behaviors of undergraduates in terms of academic procrastination, the locus of control and academic success. Journal of Education and Learning, 1(2), 288-297.

Aitken, M. E. (1982). A personality profile of the college student procrastinator. Unpublished doctoral dissertation, University of Pittsburgh, PA, USA.

Ajzen, I. (1991). The theory of planned behavior. Organizational Behavior and Human Decision Processes, 50 (2), 179-211.

Aydoğan, D. (2008). Akademik erteleme davranısının benlik saygısı, durumluluk kaygı ve öz-yeterlik ile açıklanabilirliği. Yayımlanmamıs yüksek lisans tezi, Gazi Üniversitesi, Ankara.

Akkaya, E. (2007) Academic procrastination among faculty of education students: The role of gender, age, academic achievement, perfectionism and depression. Unpublished master thesis, Middle East Technical Universitesi, Ankara.

Balkıs, M. (2006). Ögretmen adaylarının davranışlarındaki erteleme eğiliminin, düsünme ve karar verme tarzları ile ilişkisi. Yayınlanmamıs doktora tezi, Dokuz Eylül Üniversitesi, İzmir.

Balkıs, M. (2007). Öğretmen adaylarının davranışlarındaki erteleme eğiliminin, karar verme stilleri ile ilişkisi. Pamukkale Üniversitesi Ĕ̈itim Fakültesi Dergisi, 21 (1), 67-83.

Balkıs, M. \& Duru, E. (2009). Akademik erteleme davranışının öğretmen adayları arasındaki yaygınlığı, demografik özellikler ve bireysel tercihlerle ilişkisi. Eğitimde Kuram ve Uygulama, 5 (1), 18-32.

Balkıs, M. \& Duru, E. (2010). Akademik erteleme eğilimi, akademik başarı ilişkisinde genel ve performans benlik saygısının rolü. Pamukkale Üniversitesi Eğitim Fakültesi Dergisi, 27, 159-170.

Balkıs, M. \& Duru, E. (2012). Başarısızlık korkusu-benlik değri ilikisinde benlik saygısı ve erteleme eğiliminin doğrudan ve dolaylı roller. International Journal of Human Sciences [Online]. (9)2, 1075-1093.

Balkıs, M., Duru, E., Buluş, M. \& Duru, S. (2006). Üniversite öğrencilerinde akademik erteleme eğiliminin çeşitli değişkenler açısından incelenmesi. Ege Ĕgitim Dergisi, 7(2), 57-73. 
Bardi, H. \& Schwartz, S.H. (2003). Value and behavior: Strength and structure of relations. Personality and Social Psychology Bulletin, 29 (10), 1207-1220.

Beswick,G. Rothblum, E.D. \& Mann, L. (1988). Psychological antecedents of student procrastination. Australian Psychologist, 23 (2), 207-217.

Burka, J.B. \& Yuen, L.M. (1982). Mind games procrastinators play. Psychology Today, $44,32-34$.

Chaiken, S. \& Stangor, C. (1987). Attitudes and attitude change. Annual Review of Psychology, 38, 575-630.

Chissom, B. \& Iran-Nejad, A. (1992). Development of an instrument to assess learning strategies. Psychological Reports, 71 (3), 1001-1002.

Cohen, J. (1992). A power primer. Psychological Bulletin, 112 (1), 155-159.

Çakıcı, D.Ç. (2003). Lise ve üniversite ögrencilerinde genel ve akademik erteleme davranışının incelenmesi. Yayınlanmamış yüksek lisans tezi, Ankara Üniversitesi, Ankara.

Çetin, Ş. (2009). Eğitim fakültesi öğrencilerinin akademik erteleme davranışlarına ilişskin görüşlerinin incelenmesi. Gazi Üniversitesi Endüstriyel Sanatlar Eğitim Fakültesi Dergisi, 25, 1-7.

Dietz,F., Hofer, M. \& Fries, S. (2007). Individual values, learning routines and academic procrastination. British Journal of Educational Psychology, 77, 893-906.

Doyle, J. A. \& Paludi, M. A. (1998). Sex and gender: The human experience. Boston: McGrow Hill.

Ekşi, H. \& Dilmaç, B. (2010). Üniversite öğrencilerinin genel erteleme, karar vermeyi erteleme ve akademik erteleme düzeylerinin sürekli kaygı açısından incelenmesi. Uludă̆ Üniversitesi Eğitm Fakültesi Dergisi, 23 (2), 433-450.

Erdamar (Koç), G. (2010). Öğretmen adaylarının ders çalışma stratejilerini etkileyen bazı değişkenler. Hacettepe Üniversitesi Ĕ̈itim Fakültesi Dergisi, 38, 82-93.

Ferrari, J.R., Harriott, J.S., Evans, L., Lecik-Michna,D.M. \& Wenger, J.M. (1997). Exploring the time preferences of procrastinators: Night or day, which is the one? European Journal of Personality, 11 (3), 187-196.

Ferrari, J.R. \& Tice, D.M. (2000). Procrastination as a self-handicap for men and women: A task-avoidance strategy in a laboratory setting. Journal of Research in Personality, 34, 73-83

Field, A. (2009). Discovering statistics using SPSS (3rd Ed.) London: Sage Publications.

Gülebağlan, C. (2003). Öğretmenlerin isleri son ana erteleme eğilimlerinin, mesleki yeterlilik algıları, mesleki deneyimleri ve branşları bakımından karşılaştırılmasına 
yönelik bir araştırma. Yayımlanmamış yüksek lisans tezi, Ankara Üniversitesi, Ankara.

Hess, B., Sherman, M.F. \& Goodman, M. (2000). Eveningness predicts academic procrastination: The mediating role of neuroticism. Journal of Social Behavior \& Personality, 15 (5), 61-74.

Howell, A.J. \& Watson, D.C.(2007). Procrastination: Associations with achievement goal orientation and learning strategies. Personality and Individual Differences, 43, $167-178$.

Jones, C.H., Slate,J.R., Bell, S. \& Saddler, C.D. (1991). Helping high school students improve their academic skills: A necessary role for teachers. The High School Journal, 74(4), 198-202.

Kağan, M. (2009). Üniversite öğrencilerinde akademik erteleme davranışını açıklayan değişkenlerin belirlenmesi. Ankara Üniversitesi Eğitim Bilimleri Fakültesi Dergisi, 47 (2), 113-128.

Karasar, N. (2005). Bilimsel araştırma yöntemi. Ankara: Nobel Yayınları.

Klassen, R.M. \& Kuzucu, E. (2009). Academic procrastination and motivation of adolescents in Turkey. Educational Psychology: An International Journal of Experimental Educational Psychology, 29(1), 69-81.

Milgram, N., Mey-Tal, G. \& Levison, Y. (1998) Procrastination, generalized or specific, in college students and their parents. Pesonality and Individual Differences, 25, 297-316.

Onwuegbuzie, A. J. (2004). Academic procrastination and statistics anxiety. Assessment and Evaluation in Higher Education, 29, 3-19.

Önen, A.S. (2011). Investigation of students' epistemological beliefs and attitudes towards studying. Hacettepe University Journal of Education, 40, 300-309.

Özer, A. (2012). Procrastination: Rethinking trait models. Education and Science, 37 (166), 303-317.

Özer, A. \& Altun, E. (2011). Üniversite öğrencilerinin akademik erteleme nedenleri. Mehmet Akif Ersoy Üniversitesi Eğitim Fakültesi Dergisi, 11 (21), 45 - 72.

Öztürk, B., Koç, G. \& Çetin, Ş. (2004). Gazi Üniversitesi Mesleki Eğitim Fakültesi öğrencilerinin ders çalışmaya yönelik tutumları. Mesleki Ĕ̆itim Dergisi, 6 (12), 118.

Pintrich, P.R. \& De Groot, E.V. (1990). Motivational and self-regulated learning components of classroom academic performance. Journal of Educational Psychology, 82 (1), 33-40. 
Preacher, K.J. \& Hayes, A.F. (2008). Asymptotic and resampling strategies for assessing and comparing indirect effects in multiple mediator models. Behavior Research Methods, 40 (3), 879-891.

Prohaska, V., Morrill, P., Atiles, I. \& Perez, A.(2000) Academic procrastination by nontraditional students. Journal of Social Behavior \& Personality, 15 (5), 125- 135.

Rothblum, E. D., Solomon, L. J., \& Murakami, J. (1986). Affective, cognitive, and behavioral, differences, between high and low procrastinators. Journal of Counseling Psychology, 33(4), 387-394.

Senécal, C., Koestner, R. \& Vallerand, R.J. (1995). Self-regulation and academic procrastination. The Journal of Social Psychology, 135 (5), 607-619.

Shah, J.K. \& Sharma, B. (2012). A study on social maturity, school adjustment and academic achievement among residential school girls. Journal of Education and Practice, 3 (7), 69-80.

Solomon, L. J. \& Rothblum, E. D. (1984). Academic procrastination: Frequency and cognitive- behavioral correlates. Journal of Counseling Psychology, 31, 503-509.

Steel, P. (2007). The nature of procrastination: A meta-analytic and theoretical review of quintessential self-regulatory failure. Psychological Bulletin, 133(1), 65-94.

Tavşancıl, E. (2002). Tutumların ölçülmesi ve SPSS ile very analizi. Ankara: Nobel Yayınlar1.

Ulusoy, A. (2004). Güdülenme. Ayten Ulusoy (Ed.), Gelişim ve ögrenme (3.basım) (ss.307-326). Ankara: Anı Yayınc1lık.

Uzun Özer, B. (2005). Academic procrastination: Prevalance, self-reported reasons, gender difference and it's relation with academic achievement. Unpublished master thesis, Middle East Technical University, Ankara.

Uzun Özer, B. (2009). Bir grup lise öğrencisinde akademik erteleme davranışı: Sıklı̆̆ı, olası nedenleri ve umudun rolü. Türk Psikolojik Danışma ve Rehberlik Dergisi, 4 (32), 12-19.

Uzun Özer, B. (2010). A path analytic model of procrastination: testing cognitive, affective, and behavioral components. Unpublished doctoral dissertation, Middle East Technical University, Ankara.

Uzun Özer, B., Demir, A., \& Ferrari, J. R. (2009). Exploring academic procrastination among Turkish students: Possible gender differences in prevalence and reasons. Journal of Social Psychology, 149 (2), 241-257.

Washington, J. A. (2004) The relationship between procrastination and depression among graduate and professional students across academic programs: Implications for counselling. Unpublished Doctoral Dissertation, Texas Southern University, TX, USA. 
Watson, D.C. (2001). Procrastination and the five-factor model: A facet level analysis. Pesonality and Individual Differences, 30, 149-158.

Wigfield, A., \& Eccles, J. S. (2000). Expectancy-value theory of achievement motivation. Contemporary Educational Psychology, 25, 68-81.

Yeşilyurt, E. (2013). Metacognitive awareness and achievement focused motivation as the predictor of the study process, International Journal of Social Sciences and Education, 3(4), 1013-1026.

Yiğit, R. \& Dilmaç, B. (2011). Ortaöğretimde öğrencilerinin sahip oldukları insani değerler ile akademik erteleme davranışlarının bazı değişkenler açısından incelenmesi. Dumlupınar Üniversitesi Sosyal Bilimler Dergisi, 31, 159-178. 